\title{
Ecological factors affecting the fruiting success of a Tibouchina trichopoda (DC.) Baill. (Melastomataceae) flower
}

\author{
Fabiano Rodrigo da Maia ${ }^{1,2}$, Tiago Simões Malucelli ${ }^{1}$ and Isabela Galarda Varassin ${ }^{1}$
}

Submitted: 6 October, 2011. Accepted: 10 November, 2012

\begin{abstract}
The abundance and distribution of resources for pollinators modulate the reproduction of plants. This study attempted to determine whether and how the fruiting success of Tibouchina trichopoda flowers varies due to plant size, number of flowers produced, distance between individuals and cardinal orientation of the flowers. From July 2009 to February 2010 , we conducted monthly evaluations of 21 plants in an area of regenerating forest within the Atlantic Forest biome, located near the municipality of Antonina, in southern Brazil. Floral density was monitored weekly. During the study period, the species bloomed twice: once during the cool, dry season, showing an extended flowering period with scattered flowering individuals; and once during the hot, rainy season, showing a brief flowering period with a high density of flowering individuals. Plant size was not found to influence fruiting success. There was greater production of flowers and fruits during the brief flowering period. The extent of the floral display positively affected the fruiting success of the flowers, the effect being greater when the density of flowers was low and tending to stabilize at higher densities. The northern-facing portions of tree crowns produced more flowers and therefore had greater fruiting success than did the southern-facing portions. However, the proportion of fruits produced per flower was the same.
\end{abstract}

Key words: resource allocation, Atlantic Rainforest, plant-pollinator interactions, population density, floral longevity

\section{Introduction}

The energy available to a plant is divided between growth and reproduction (Roff, 2002). The proportion of that energy allocated to reproduction is known as reproductive effort, which, in fruit-bearing species, is initially directed to flower production. Such plants expend a considerable amount of energy in floral construction (Schoen \& Ashman 1995), in the maintenance of flowers (Ashman \& Schoen 1994) and the production of floral resources (Ashman \& Schoen 1997). Therefore, fruiting success is influenced by many factors, such as those related to reproductive effort and the effects of floral display on pollinators, which can be observed in fruit production (Stephenson 1981; Susko \& Lovett-Doust 1999).

Light availability tends to affect the fruiting success of plants. In low-light conditions, there is greater resource allocation to structures that optimize or even increase the capture of light, such as leaves and stems (Kilkenny \& Galloway 2008). In addition, light availability can modulate the fruiting success of plant species by influencing pollinator behavior (Kilkenny \& Galloway 2008). Hence, a difference in reproductive allocation in relation to the cardinal orientation of the flower is expected.
Flowers located in patches where more resources are available might have greater fruiting success, because extensive floral displays increase the number and variety of pollinators (Thompson, 2001). At the population level, plant distribution represents an important strategy that also influences reproductive success by altering pollinator response to these factors (Feisinger et al.; 1991).The floral display of one or several individuals have profound effects on the reproductive success of a plant. An increase in the number of open flowers can enhance the chances of floral visitation (Grindeland et al. 2005), because pollinators are more likely to move between individuals in dense populations. In dense populations, the flight distance between individuals is shorter than in sparse populations, in which pollinators are more likely to visit multiple flowers on the same plant, thus favoring pollen transfer within the same plant (de Jong et al. 1993). However, an increase in the extent of the floral display can increase competition between individual flowers, decreasing the chances of pollination (Rathcke 1988). After a certain density has been reached, the number of flowers is larger than the pollinators are able to visit, resulting in competition for floral visitors (Rathcke 1983), reducing the deposition of compatible pollen in the flowers (Feisinger et al.1991). In addition, small plant populations

\footnotetext{
${ }^{1}$ Universidade Federal do Paraná, Departamento de Botânica, Laboratório de Ecologia Vegetal, Curitiba, PR, Brazil

${ }^{2}$ Author for correspondence: fabiano.botanica@gmail.com
} 
are less attractive to pollinators than are large ones. Therefore, in small populations, there can be insufficient pollen transfer, decreasing the probability of successful seed production (Ågren 1996).

Tibouchina, a genus belonging to the family Melastomataceae, has 350 species distributed throughout the tropical and subtropical regions of the Americas (Wurdack 1962). Tibouchina trichopoda (DC.) Baill. is a pioneer species that occurs in coastal lowlands, in swampy areas of Quaternary plains, in pioneer formations influenced by the sea, as well as in open areas of lowland tropical rain forest (Meyer et al. 2010). Various studies of the reproductive biology of Melastomataceae species have noted the occurrence of apomixis (Renner 1989; Goldenberg \& Shepherd 1998). Mechanisms of self-incompatibility and apomixis are common in the family, but usually do not occur in the tribe Melastomeae, of which Tibouchina is a member (Goldenberg \& Shepherd 1998). Preliminary information (T.S. Malucelli, unpublished data) indicates that T. trichopoda is self-compatible, with no fruit production from apomixis, which could explain the dependence on pollinators for reproduction. T. trichopoda is pollinated by bees belonging to the genera Augochloropsis, Bombus, Centris, Thygater and Xylocopa (T.S. Malucelli, unpublished data). In this context, the aim of this study was to determine whether and how the fruiting success of a T. trichopoda flower is affected by the following: plant size; the number of flowers produced (extent of the floral display); the distance between individuals; and the cardinal orientation of flowers. An additional objective was to determine whether flower production is affected by cardinal orientation.

\section{Material and methods}

\section{Study area}

The study was conducted between July 2009 and February 2010, in the Rio Cachoeira and Morro da Mina Nature Reserves, both located near the municipality of Antonina $\left(25^{\circ} 19^{\prime} 15^{\prime \prime} \mathrm{S} ; 45^{\circ} 42^{\prime} 24^{\prime \prime} \mathrm{W}\right)$, on the northern coast of the state of Paraná, in southern Brazil (IPARDES 2001). The reserves are located within the Guaraqueçaba Environmentally Protected Area, which is part of the Atlantic Forest biome. Both are private properties, belonging to the Society of Wildlife Research and Environmental Education. According to the Köppen climate classification system, the climate of the region is divided between mesothermal humid subtropical (type $\mathrm{Cfa}$ ) in the mountain areas, where the average temperature is $18^{\circ} \mathrm{C}$ in the colder months and $22^{\circ} \mathrm{C}$ in warmer months, and tropical wet (type Af) on the plains, where the average annual temperature is $21.1^{\circ} \mathrm{C}$ (IPARDES 2001). The areas under study were mainly forest remnants and areas that had been undergoing secondary succession for 2-10 years, including abandoned pastures and areas of natural regeneration (SPVS/TNC 2000).

\section{Procedures}

To assess individual and landscape effects on fruit production (here referred to as fruiting success), we selected 21 T. trichopoda individuals. The plants were monitored on a monthly basis. The individuals studied were between 2.5 and $4.0 \mathrm{~m}$ in height, with crowns averaging $3.5 \mathrm{~m}$ in diameter. We accessed the crowns with a 2.5 -m ladder, and we marked 20 flowers in the two primary cardinal orientations (northern and southern exposures, a total of 40 flowers per individual). To evaluate fruiting success, we considered the ripe fruits (those which remained one month in the mother plant). Fruits lost before this period were classified as aborted. The T. trichopoda individuals were randomly sampled and observed during the two flowering periods that occurred during the study period. In terms of the diameter at their base, there was no difference among the plants that bloomed during each flowering period $(\mathrm{F}=0.01 ; \mathrm{GL}=20 ; \mathrm{p}>0.05)$. To evaluate a possible effect of plant size on fruit production, we determined the basal diameter (BD) of each plant by first measuring the circumference with a measuring tape and converting the values obtained to diameter. The influence of $\mathrm{BD}$ on the fruiting success of individuals was tested using regression analysis.

The effect of cardinal orientation on the allocation of reproductive structures was first assessed by quantifying the number of fruits developing from marked flowers. In addition, the production of flowers in each cardinal orientation was assessed by counting all flowers located in a standardized layer of the plant (lower third of the crown), in order to quantify flower production (floral density) for each orientation. Flower production was monitored for one month, during which the new flowers produced were counted on a weekly basis and the sum of the four counts was obtained. Because the study area is located south of the Tropic of Capricorn, the majority of the direct sunlight comes from the north. Therefore, we chose to evaluate the northern and southern exposures because they present the greatest contrast in terms of light availability. Using the residuals from the regression analysis of the production of flowers and fruits, i.e. eliminating the effect of floral density on reproductive success, we tested the existence of differences in fruit set between the two exposures. To determine whether there was a variation in flower availability, the difference between northern and southern exposure, in terms of the mean reproductive success, was compared by a t-test.

To assess whether the greater flower production per individual affects the fruit set, the relationship between the number of available flowers during fruit formation monitoring and the number of fruits produced was evaluated. The relationship between the two variables was determined by regression analysis.

\section{Results}

During our field observations, the group of T. trichopo$d a$ individuals evaluated presented two flowering periods, 
different individuals flowering during each period. The first occurred between August and September (during the cold, dry season), when the group showed an extended flowering period. During that period, flowering individuals showed no spatial aggregation and it was common to find a single flowering individual in the middle of the forest. The second occurred between November and mid-February (during the hot, rainy season), when there was brief flowering at the individual level. The phenological pattern observed during the brief flowering period was intense flowering activity, together with simultaneity in the production and maturation of nearly all inflorescences of a given plant. The interaction between these events resulted in mass production of flowers, so that the crowns of the trees were completely purple. In this brief flowering period, many individuals flowered at the same time and in dense patches, each remaining in bloom for approximately 20 days. In mid-January, the total number of flowers decreased, and all of the plants were fruiting or dispersing seed by the beginning of February. In addition, by the end of this flowering period, most of the individuals had dropped some of their leaves, leaving the branches relatively bare, with mostly fruits. As can be seen in Fig, 1A, the number of flowers produced in the lower third of the crown was lower during the extended period of flowering than during the brief flowering period (50.5 flowers.plant ${ }^{-1}$. month $^{-1}$ vs. 135.9 flowers.plant ${ }^{-1}$. month $^{-1}$ ), the difference between the two periods being significant $\left(r^{2}=0.30 ; t=-3.14 ; G L=20 ; p=0.0051\right)$. Fig. 1B shows that, because the availability of flowers was lower during the extended flowering period than during the brief flowering period, the fructification rate was also significantly lower during the former than during the latter $(15 \%, 120$ fruits vs. $58 \%, 468$ fruits $\left.-r^{2}=0.62 ; t=-5.94 ; G L=20 ; p<0.0001\right)$.

Fruiting success did not vary significantly in relation to $\mathrm{BD}\left(\mathrm{r}^{2}=-0.04 ; \mathrm{F}=0.02 ; \mathrm{GL}=1,20 ; \mathrm{p}>0.05\right)$, individuals with both high and low reproductive allocation being observed. Likewise, the distance between individuals, which ranged from $0.27 \mathrm{~m}$ to $11.05 \mathrm{~m}$, did not influence fruiting success $\left(\mathrm{r}^{2}=-0.05 ; \mathrm{F}=0.03 ; \mathrm{GL}=1,20 ; \mathrm{p}>0.05\right)$. An increase in floral density from 5 to 50 flowers increased fruiting success considerably (from 15\% to 32\%), whereas an increase from 100 to 200 flowers increased fruiting success only slightly (from 40 to $44 \%$ ), as can be seen in Fig. 1C. Therefore, fruiting success increased with floral density, although this effect was greater within the lower range of floral density $\left(r^{2}=0.49 ; \mathrm{F}=19.26 ; \mathrm{GL}=1,18 ; \mathrm{p}=0.0004\right)$. There was a trend toward the stabilization of fruiting success at high floral densities (Fig. 1C).

In both flowering periods, northern exposure resulted in greater production of flowers (Fig. 1D) and fruits (Fig. 1E). Nevertheless, as can be seen in Fig. 1F, excluding the effect that increased floral availability had on the fruiting success, northern and southern exposures produced the same number of fruits, proportional to the number of flowers $(\mathrm{t}=-0.81 ; \mathrm{GL}=40 ; \mathrm{p}>0.05)$.

\section{Discussion}

We found that T. trichopoda had a sub-annual flowering pattern (sensu Newstron et al. 1994). The distribution of floral resources to more than one period during the year might increase pollinator loyalty and reduce competition among floral visitors (Bullock \& Solís-Magallanes 1990). In fact, the brief flowering period of T. trichopoda coincides with the flowering period of T. pulchra (which blooms from November to mid-February), with which it shares the same pollinators (Pereira et al. 2011; A. C. Pereira, personal observations). The differences observed during the two T. trichopoda reproductive flowering periods might be associated with the spatial distribution of flowering individuals. In the extended flowering period, characterized by scattered individuals in the forest, pollinators tend to alternate between plants with a lower frequency and visit more flowers on the same plant (Heinrich 1979; Zimmerman 1981). This higher number of visits results in a higher number of pollination events, as well as increasing the likelihood of geitonogamy (van Treuren et al. 1993). In the brief T. trichopoda flowering period, during which there is great aggregation of flowering individuals and the flights between individuals within the same patch are facilitated, there is a greater probability of cross-pollination. In T. trichopoda, fruiting success was greater in individuals with high flower availability. The fact that fruiting success increases with the increasing availability of flowers and that the effect is greater when floral density is low shows that the relationship is not linear. Montenegro \& Cavieres (2006) also suggested that there is a nonlinear relationship between floral density and fruiting success, possibly due to intraspecific (interindividual) competition among pollinators in settings of high floral density (Feldman et al. 2004). Although elevated floral densities lead to a higher number of pollinator visits, this increase is not necessarily proportional to the increase in the number of flowers (Klinkhamer et al. 1989). Therefore, in T. trichopoda, small variations in floral density (of $\leq 50$ flowers) result in large differences in fruiting success when floral density is low (Fig. 1B). In addition, the high fruit set following the brief flowering period might have occurred due to the high density of flowering individuals, which formed clusters within the forest (Montenegro \& Cavieres 2006) and attracted more pollinators. In general, plants located in areas with abundant floral resources are more frequently visited and have superior fruiting success (Feinsinger et al. 1991; Thompson 2001, Klinkhamer \& van der Lugt 2004). Populations with high floral density would be easily perceived by their pollinators (Kawarasaki \& Hori 1999), especially those that focus their activity on populations where a large amount of resources are available, in order to minimize energy expenditure (MacArthur \& Pianka 1966). This would allow pollinators to optimize their trade-off between the costs and benefits of their flights to gather resources (Klinkhamer \& van der Lugt 2004). The fact that a greater number of bees were registered during the 
A

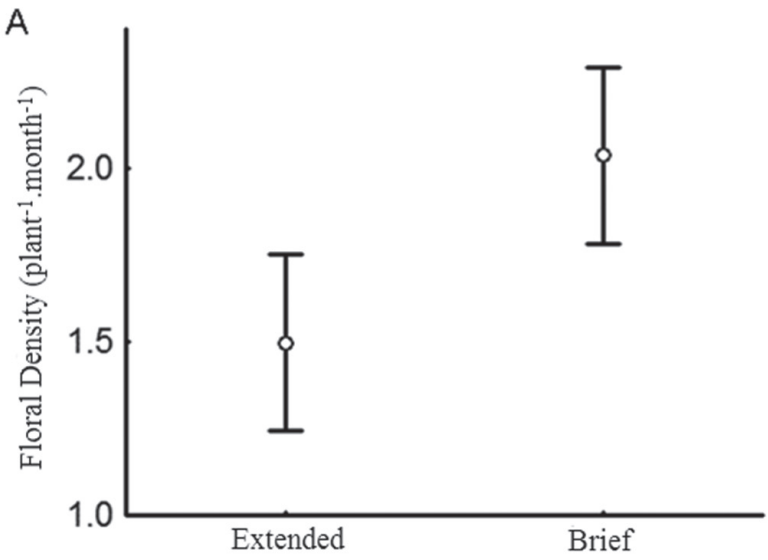

$\mathrm{C}$

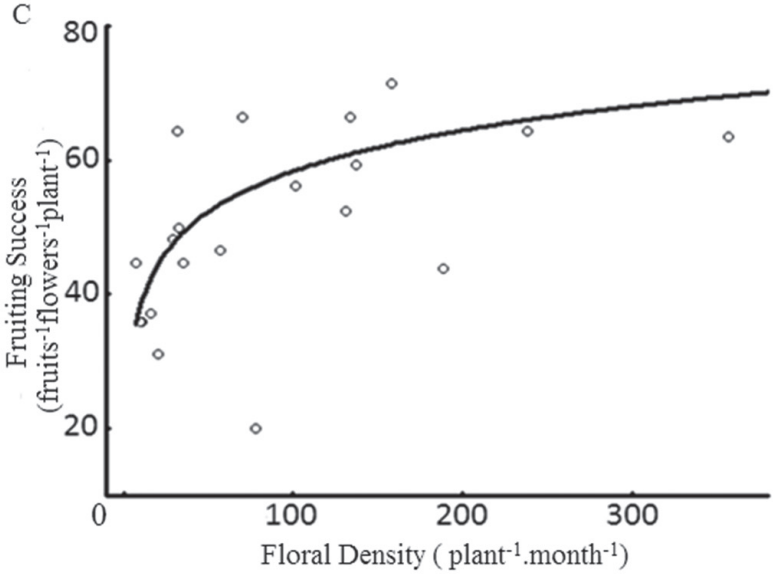

E

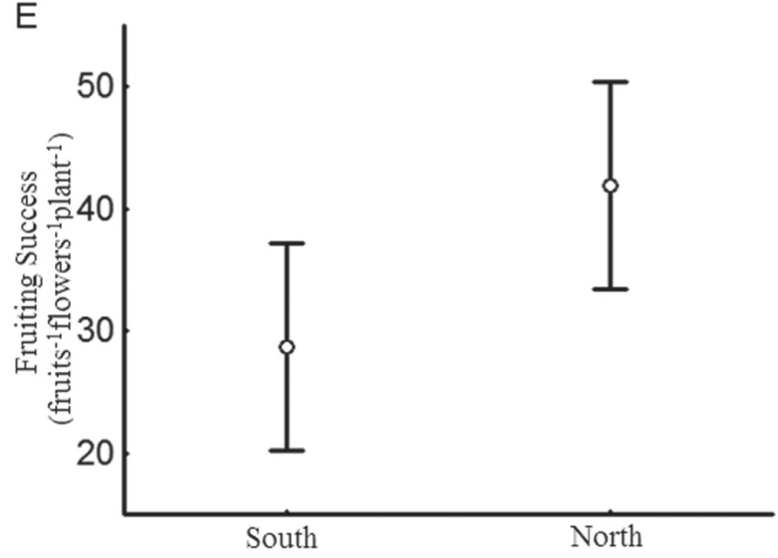

B

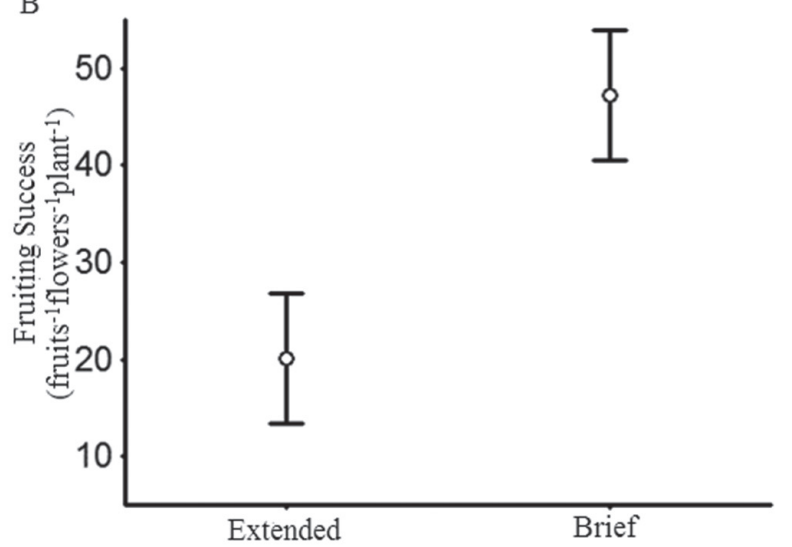

D
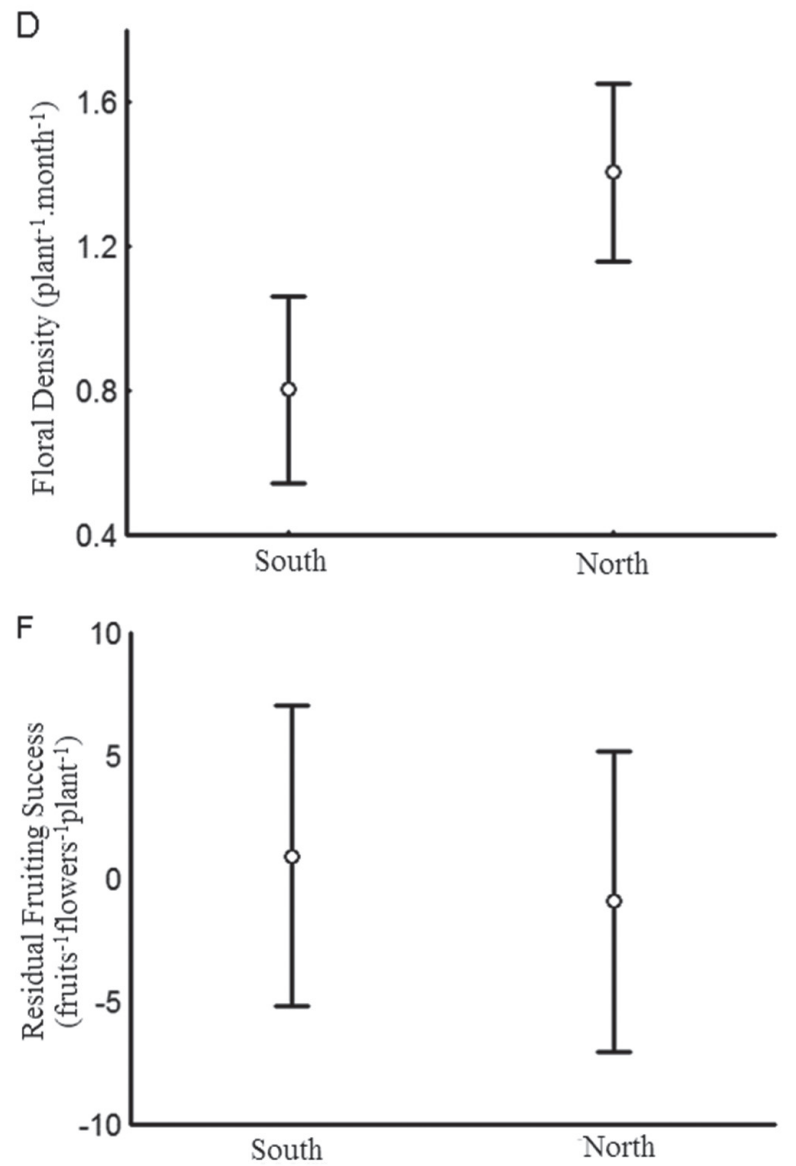

Figure 1. Reproductive variations in Tibouchina trichopoda (DC.) Baill. A. Variation in floral density (log-transformed) in both flowering periods. B. Variation in fruiting success (arcsine-transformed) in both flowering periods. C. Variation in fruiting success as a function of the mean floral density at the at the lower third of the crown (Fruiting success $[\log ]=-3.56+0.55$ floral density $[\log ]$ ) D. Floral density variation $(\log$-transformed) as a function of cardinal orientation. E. Fruiting success variation (arcsine-transformed) as a function of cardinal orientation. F. Residual variation of fruiting success as a function of the variation in cardinal variation.

brief flowering period than during the extended flowering period also suggests a change in local abundance of the bee fauna at this time. There appears to be a reduction in the bee population in subtropical and dry areas during winter (Rebelo \& Garofalo 1991; Rebelo 1995), which is reflected in the diversity of bees visiting the flowers of legumes (Arroyo 1981). The greater availability of flowers on the north side of the plants evaluated in the present study is probably due to the greater light availability in this region, which is especially relevant for species in subtropical locations. In fact, plants exposed to more light produce more flowers than do plants exposed to a reduced amount of light (Verburg \& During 1998). In the present study, the increased availability of northern-facing flowers, when compared with that of southern-facing flowers, resulted in greater reproductive success. However, in T. trichopoda, the greater number of 
fruits on the plant sides receiving northern exposure is due only to the fact that the plants have more flowers on that side.

In T. trichopoda, the probability of fruiting success of a given flower depends on the floral density of its surroundings and the cardinal orientation of the flower in the crown. A single flower within a sparse population of flowering individuals with low floral density in the crown and receiving southern exposure is less likely to form a fruit than a flower in a dense population of flowering individuals with high floral density in the crown and receiving northern exposure.

\section{Acknowledgements}

We thank the Universidade Federal do Paraná (UFPR, Federal University of Paraná) for the opportunity to do this research and for the use of the Plant Ecology Laboratory. We are grateful to Aline da Danieli-Silva, Jana Magaly T. de Souza and Valeria C. Muschner for the helpful comments provided. We also thank the Society of Wildlife Research and Environmental Education for the logistic support at the Rio Cachoeira and Morro da Mina Nature Reserves.

\section{References}

Ågren, J. 1996. Population size, pollinator limitation, and seed set in the self-incompatible herb Lythrum salicaria. Ecology 77: 1779-1790.

Arroyo, M.T.K. 1981. Breeding systems and pollination biology in Leguminosae. Pp.723-769. In: Polhill, R.M. \& Raven, P.H. (Ed.)-part 2. Advances in Legume Systematics. Royal Botanic Gardens, Kew.

Ashman, T.L. \& Schoen, D.J. 1994. How long should flowers live? Nature 371: 788-791.

Ashman, T.L. \& Schoen, D.J. 1997. The cost of floral longevity in Clarkia tembloriensis: an experimental investigation. Evolutionary Ecology 11: $289-300$

Bullock, S.H. \& Solis-Magallanes, A. 1990. Phenology of canopy trees of a tropical deciduous forest in Mexico. Biotropica 22: 22-35.

de Jong, T.J.; Waser, N.M. \& Klinkhamer, P.G.L. 1993. Geitonogamy: the neglected side of selfing. Trends in Ecology and Evolution 8: 321-325.

Feinsinger, P.; Tiebout III, H.M. \& Young, B.E. 1991. Do tropical birdpollinated plants exhibit density-dependent interaction? Ecology 72: 1953-1963.

Feldman, T.S.; Morros, W.F. \& Wilson, W.G. 2004. When can two plant species facilitate each other's pollination? Oikos 105: 197-212.

Goldenberg, R. \& Shepherd, G.J. 1998. Studies on the reproductive biology of Melastomataceae in "cerrado" vegetation. Plant Systematics and Evolution 211: 13-29.

Grindeland, J.M.; Sletvold, N. \& Ims, R.A. 2005. Effects of floral display size and plant density on pollinator visitation rate in a natural population of Digitalis purpurea. Functional Ecology 19: 383-390.

Heinrich, B.1979. Resource heterogeneity and patterns of movement in foraging bumblebees. Oecologia 40: 235-245.

IPARDES - Instituto Paranaense de Desenvolvimento Social. 2001. Zoneamento da Área de Proteção Ambiental de Guaraqueçaba. Curitiba, IPARDES.

Kawarasaki, S. \& Hori, Y. 1999. Effect of flower number on the pollinator attractiveness and the threshold plant size for flowering in Pertya triloba (Asteraceae). Plant Species Biology 14: 69-74.
Kilkenny, F.F. \& Galloway, L.F. 2008. Reproductive success in varying light environments: direct and indirect effects of light on plants and pollinators. Oecologia 155: 247-255.

Klinkhamer, P.G.; de Jong, T.J. \& de Bruyn, G.J. 1989. Plant size and pollinator visitation in Cynoglossum officinale. Oikos 54: 201-204.

Klinkhamer, P.G. \& van der lugt, P.P. 2004. Pollinator service only depends on nectar production in sparse populations. Oecologia 140: 491-494.

MacArthur, R.H. \& Pianka, E.R. 1966. On the optimal use of a patchy environment. American Naturalist 100: 603-609.

Meyer, F.S.; Goldenberg, R. \& Guimarães, P.J.F. 2010. Tibouchina (Melastomataceae) do estado do Paraná, Brasil. Rodriguésia 61: 615-638.

Montenegro, M.A.M. \& Cavieres, L.A. 2006. Effect of density and flower size on the reproductive success of Nothoscordum graminum (Alliaceae). Gayana Botánica 63:93-98.

Newstron, L.E.; Frankie, G.W. \& Baker, H.G. 1994. A new classification for plant phenology based on flowering patterns in lowland tropical rain forest trees at La Selva, Costa Rica. Biotropica 26: 141-159.

Pereira, A.C.; Silva, J.B.; Goldenber, R.; Melo, G.A.R. \& Varassin, I.G. 2011. Flower color change accelerated by bee pollination in Tibouchina (Melastomataceae) Flora 206: 491-497.

Rathcke, B.J. 1983. Competition and facilitation among plants for pollination. Pp. 305-329. In: L. Real (ed.). Pollination Biology. New York, Academic Press.

Rathcke, B.J. 1988. Interactions for pollination among coflowering shrubs. Ecology 69: 446-457.

Rebêlo, J.M.M. 1995. Espécies de Anthophoridae (Hymenoptera, Apoidea) e sua associação com flores, numa área restrita da Ilha de São Luís-MA, Brasil. Boletim do Museu Paraense Emílio Goeldi, série Zoologia 11: 105-124.

Rebêlo, J.M.M. \& Garófalo, C.A. 1991. Diversidade e sazonalidade de machos de Euglossini (Hymenoptera. Apidae) e preferência por iscasodores em um fragmento de floresta, no sudeste do Brasil. Revista Brasileira de Biologia 5: 787-799.

Renner, S.S. 1989. A survey of reproductive biology in neotropical Melastomataceae and Memecylaceae. Annals of the Missouri Botanical Garden 76: 496-518.

Roff, D.A. 2002. The evolution of life history: theory and analysis. New York, Chapman and Hall.

Schoen, D.J. \& Ashman, T.L. 1995. The evolution of floral longevity: resource allocation to maintenance versus construction of repeated parts in modular plants. Evolution 49: 131-139.

SPVS/TNC (Sociedade de Pesquisa em Vida Selvagem e Educação Ambiental/The Nature Conservancy). 2000. Projeto de Restauração da Floresta Atlântica. Curitiba.

Stephenson, A.G. 1981. Flower and fruit abortion: proximate causes and ultimate Functions. Annual Review of Ecology and Systematics 12: 253-279.

Susko D.J. \& Lovett-Doust, L. 1999. Effects of resource availability, and fruit and ovule position on components of fecundity in Alliaria petiolata (Brassicaceae). New Phytologist 144: 295-306

Thompson, J.D. 2001. How visitation patterns vary among pollinators in relation to floral display and floral design in a generalist pollination system. Oecologia 126: 386-394.

van Treuren, R., Ouborg, N.J. \& van Delden, W. 1993. The effects of population size and plant density on outcrossing rates in locally endangered Salvia pratensis. Evolution 47: 1094-1104.

Verburg, R.W. \& During, H.J. 1998. Vegetative propagation and sexual reproduction in the woodland understory pseudo-annual Circaea lutetiana L. Plant Ecology 134: 211-224.

Wurdack, J.J. 1962. Melastomataceae of Santa Catarina. Sellowiana 14: 109-217.

Zimmerman, M. 1981. Optimal foraging, plant density and the marginal value theorem. Oecologia 49: 148-153. 